
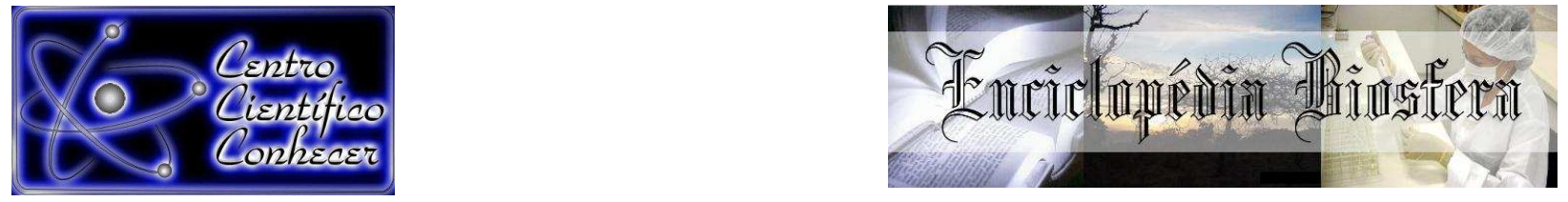

\title{
ASPECTO ALIMENTAR E REPRODUTIVO DO Corydoras aeneus (GILL, 1858), DO CÓRREGO RUSSO, TANGARÁ DA SERRA - MT
}

\author{
${ }^{1}$ Talitha Hevilla de Souza, ${ }^{3}$ Divina Sueide de Godoi, ${ }^{1}$ Tassiana Andruchak de \\ Azevedo, ${ }^{2}$ Auclar Felipe Botini, ${ }^{4}$ Luiz Antônio Jacyntho
}

${ }^{1}$ Bióloga, Universidade do Estado de Mato Grosso, Universidade do Estado de Mato Grosso, MT 358 Km 07, Jardim Aeroporto, 78300-000 Tangará da Serra, MT, Brasil.E-mail: talithaa.h@hotmail.com

${ }^{2}$ Mestrando em Genética e Melhoramento de Plantas (PGMP), Universidade do Estado de Mato Grosso, MT 358 Km 07, Jardim Aeroporto, 78300-000 Tangará da Serra, MT, Brasil.

${ }^{3}$ Doutora em Aquicultura, Departamento de Ciências Biológicas da Universidade do Estado de Mato Grosso, MT 358 Km 07, Jardim Aeroporto, 78300-000 Tangará da Serra, MT, Brasil.

${ }^{4}$ Doutor em Engenharia Elétrica, Departamento de Matemática da Universidade do Estado de Mato Grosso, Rua A, S/n, Cohab São Raimundo, Barra do Bugres - MT, Brasil, CEP: 78.390-000, Caixa postal 92

\section{Recebido em: 03/10/2016 - Aprovado em: 21/11/2016 - Publicado em: 05/12/2016 DOI: 10.18677/EnciBio 2016B 106}

Estudos sobre diversidade da ictiofauna na região neotropical ainda estão incompletos, anualmente novas espécies são descritas e diversas alterações do ecossistema hídrico tem ocorrido, grandes fatores podem ocasionar mudanças nessas informações. Este trabalho tem objetivo avaliar o aspecto alimentar e reprodutivo do Corydoras aeneus durante a cheia e seca, no córrego Russo, no município de Tangará da Serra, MT. As coletas foram realizadas mensalmente de outubro de 2014 a setembro de 2015, os exemplares foram capturados numa peneira de ferro, com $90 \mathrm{~cm}$ de largura e 1,80 m de comprimento com malha de 2 $\mathrm{mm}$, realizando $2 \mathrm{~h}$ de esforço por coleta. Foram analisados 63 indivíduos, sendo 23 fêmeas e 40 machos. A biometria foi realizada com paquímetro para o comprimento padrão e altura. Para determinação da dieta da espécie foram utilizados os métodos de Frequência de Ocorrência (FO), Frequência Volumétrica (FV), Índice de Importância Alimentar (IAi) e o Grau de Repleção (GR). Foi analisado também o tipo de sexo e o estádio de maturação gonadal. Realizou-se teste de KolmogorovSmirnov para determinar se a população apresentava uma distribuição normal durante os dois períodos. Foram identificadas quatro categorias alimentares, resto animal; recursos vegetais; restos de insetos e detritos. Recurso vegetal foi o item que apresentou a maior $\mathrm{FO}$ e IAi, durante o período de seca, sendo $74,28 \%$ e $80 \%$ respectivamente, no período da chuva houve modificação no seu hábito alimentar, resto de inseto apresentou maior $\mathrm{FO}$ e IAi, respectivamente 46,43\% 60,13\%, portanto, esses itens foram considerados principais em sua dieta.

PALAVRAS-CHAVE: Hábito alimentar; Ictiofauna; Recursos Vegetais 


\title{
ASPECT OF FOOD AND REPRODUCTION Corydoras aeneus (Gill, 1858), BROOK RUSSO, TANGARÁ DA SERRA, MT
}

\begin{abstract}
Studies on diversity of fish populations in the Neotropics are still incomplete, every year new species are described and various changes in water ecosystem occurred, major factors can cause changes in such information. This study aimed to evaluate the feeding and reproductive behavior of Corydoras aeneus during floods and droughts in the Russian creek in the city of Tangara da Serra, MT. Samples were collected monthly from October 2014 to September 2015, were caught in an iron sieve, $90 \mathrm{~cm}$ wide and $1,80 \mathrm{~m}$ long with $2 \mathrm{~mm}$ mesh, making effort $2 \mathrm{~h}$ for each collection. We analyzed 63 subjects, 23 females and 40 males. Biometrics was performed using a standard length caliper and height. To determine the type of diet we used the frequency of occurrence of methods (FO), Volumetric Frequency (VF), Food Index (IAI) the degree of repletion (GR). It was also analyzed the type of sex and gonadal maturation stage. The Kolmogorov-Smirnov test was used to determine if the population showed a normal distribution during the two periods. Four categories of food were identified, animal resources; plant resources; remains of insects and debris. Plant resources was the item with the highest $\mathrm{FO}$ and $\mathrm{IAi}$ during the dry season, with $74,28 \%$ and $80 \%$, respectively, in the rainy season there was a change in your eating habits, insect remains showed higher FO and IAi respectively $46,43 \%$ $60,13 \%$, so these items were considered principal in your diet.
\end{abstract}

KEYWORDS: Ichthyofauna; Food habits; Plant resources

\section{INTRODUÇÃO}

Atualmente são conhecidos em torno de 32.500 espécies de peixes no mundo, e aproximadamente $41 \%$ são de água doce. A região Neotropical possui $50 \%$ da ictiofauna de água doce descrita das quais o Brasil abriga cerca de $43 \%$ dessa ictiofauna conhecida (FROESE \& PAULY, 2013). O conhecimento sobre a diversidade de peixes é ainda incompleto, anualmente novas espécies são descritas, portanto, é de se prever que a riqueza total efetiva seja ainda muito maior (SERRA et al., 2014).

Na América do Sul está concentrado o maior volume de água doce do mundo, apresentando rios com grandes extensões, larguras e profundidades. No estado de Mato Grosso estão localizadas três bacias hidrográficas muito importantes: bacia Amazônica, bacia do Tocantins e a bacia Platina. A bacia Amazônica é representada pelo rio Amazonas e os seus principais rios são rio Xingu, rio Guaporé e rio Teles Pires. O rio Araguaia da bacia do Tocantins corta toda a parte da fronteira leste que fica entre Mato Grosso e Goiás com $2.115 \mathrm{~km}$ de extensão formando a maior ilha fluvial do mundo a ilha do bananal (LIRA, 2011).

A bacia Platina é representada em Mato Grosso pelo rio Paraguai que nasce no complexo de Chapada dos Parecis e tem afluentes como os rios Bento Gomes, Cabaçal, Cuiabá, Jauru, Queimado e Sepotuba. Esses rios abrangem vários municípios como Barra do Bugres, Porto Estrela, Nova Olímpia, Cáceres, Tangará da Serra entre outros (SOUZA et al., 2011)

Os mesmos autores descrevem que a vegetação mato-grossense está contida em três grandes domínios biogeográficos: os Cerrados, as Florestas e o Pantanal, os quais se encontram inseridos na região de clima tropical e equatorial, apresentando diversidade de paisagens decorrente das variações climáticas ao 
longo do ano em função da atuação dos sistemas atmosféricos e das interações entre superfície e atmosfera.

Conforme DALLACORT et al., (2011), a região de Tangará da Serra - MT apresenta duas estações bem definidas, uma estação seca de maio a setembro e outra chuvosa de outubro a abril, assim foi possível obter os dados referentes a cada uma delas. Há uma crescente alteração dos ecossistemas hídricos, como desmatamentos, interferência do homem, mudanças climáticas, grandes fatores que podem ocasionar mudanças nas informações locais (VASCONCELOS et al., 2011). SOUZA et al., (2014) afirmam que as influências antrópicas no ecossistema aquático sofrem muitos impactos, tanto próximo as áreas urbanas quanto em áreas distantes o que pode influenciar negativamente os parâmetros ecológicos de diversidade de espécies. A cadeia alimentar e a dinâmica reprodutiva das espécies são os aspectos que mais sofrem com essas mudanças, uma vez que a mata ciliar é uma importante fonte de alimento e abrigo para a fauna aquática (GANDINI et al., 2012).

O período de reprodução e o tipo de desova são características específicas essenciais para a manutenção de qualquer espécie de peixe, de modo a garantir o equilíbrio populacional (CHELLAPPA et al., 2013). Segundo BARROS et al., (2016), normalmente a dinâmica reprodutiva ocorre logo após as chuvas, associadas ao aumento da temperatura, nível dos rios e lagos e a disponibilidade de alimento no local.

Ultimamente vêm sendo realizados diversos estudos sobre dieta dos animais de ecossistemas aquáticos, por ser ampla a área de estudos. O conhecimento sobre o hábito alimentar dos peixes possibilita a compreensão das informações da ictiofauna do local, e também a escolha do alimento mais apropriado para as necessidades nutricionais dos peixes (CANAN et al., 2011; CANAN et al., 2012; PESSOA et al., 2013).

A espécie Corydoras aeneus descrita por Gill em 1858, pertence à ordem Siluriformes e a família Callichthyidae, pode ser encontrada na região neotropical. É conhecido como peixe-gato blindado, por possuir o corpo coberto com placas ósseas disposta em duas séries no flanco, possui boca pequena, e um par de barbilhões em cada canto da boca, podendo chegar a medir $70 \mathrm{~mm}$ de comprimento. A parte dorsal da cabeça e do tronco é escura e o ventre claro. Possui uma faixa castanha escura muito larga da parte anterior do tronco até o pedúnculo caudal, às vezes com limites indefinidos e confunde-se com a cor de fundo. Em vida, apresenta um reflexo azulado, esverdeado e amarelado em cada placa do flanco (BRITSKI, et al., 2007). O presente trabalho teve por objetivo avaliar o aspecto alimentar e reprodutivo do Corydoras aeneus, nas diferentes épocas sazonais do ano (cheia e seca) no córrego Russo, localizado no município de Tangará da Serra, MT.

\section{MATERIAL E MÉTODOS}

\section{Área de estudo}

As coletas foram realizadas no córrego Russo, localizado no município de Tangará da Serra, Mato Grosso (Coordenadas geográficas 1436’38.11"5 57우우․18”) (Figura 1). 

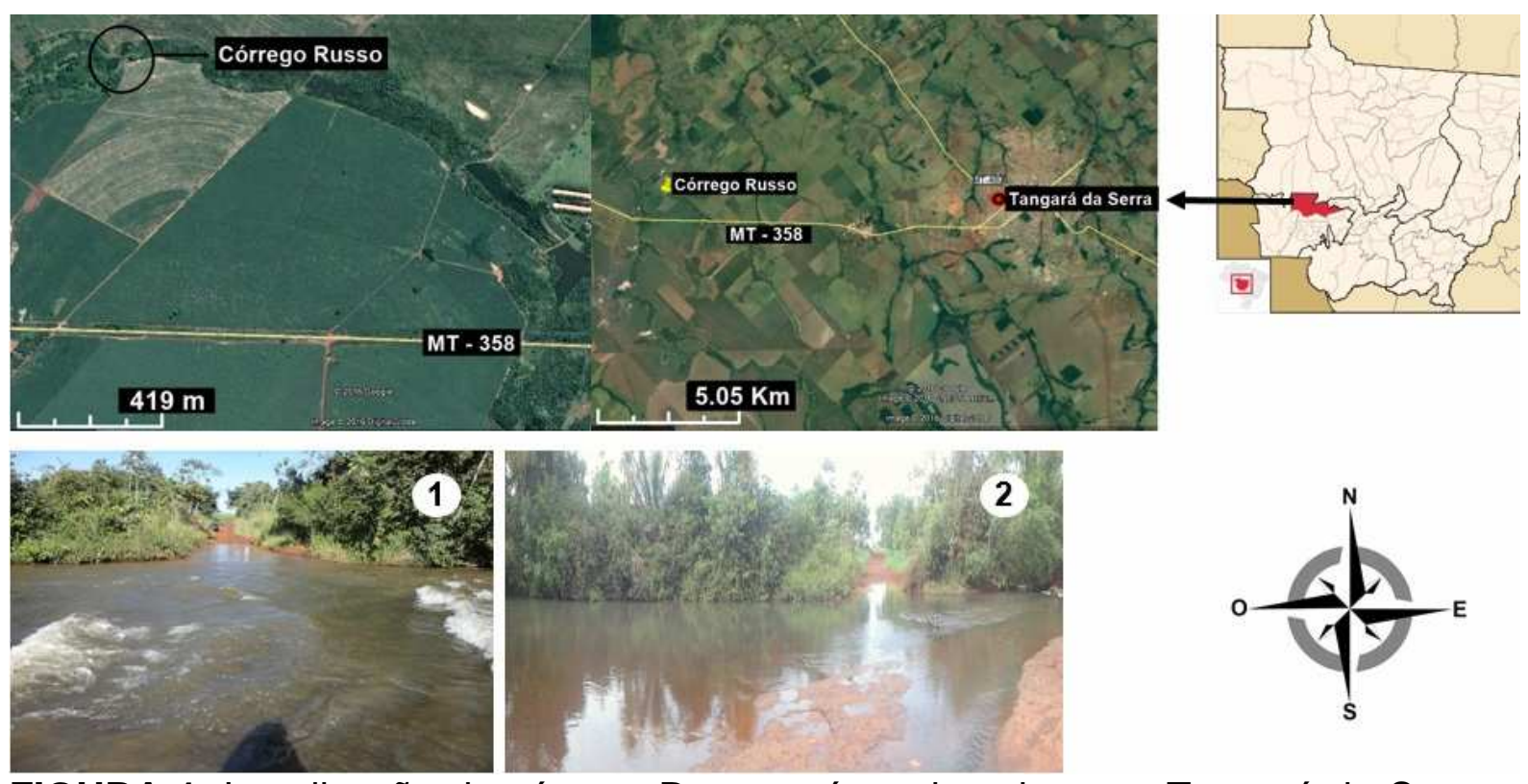

FIGURA 1. Localização do córrego Russo e área de coleta em Tangará da Serra MT, (1) Período de cheia e (2) Período de seca. Fonte: Foto obtida através do Google TM Earth.

\section{Coleta}

Para realizar a coleta dos exemplares foram aplicados dois métodos de captura, o primeiro através do uso de duas tarrafas, com malha $12 \mathrm{~mm}$, com 1,40 m de altura e $5 \mathrm{~m}$ de diâmetro e o segundo através de uma peneira de ferro com malha $2 \mathrm{~mm}$, com 1,80 de comprimento e $90 \mathrm{~cm}$ de largura, sendo que para cada método foi realizado $2 \mathrm{~h}$ de esforço por coleta. Os exemplares capturados foram colocados em sacos plásticos, anestesiados com Eugenol, e fixados em solução de formol à $10 \%$ decorridas $72 \mathrm{~h}$ transferidos para álcool $70 \%$. As coletas foram realizadas mensalmente no período de 1 ano em apenas um ponto do córrego Russo, tendo início em outubro de 2014 e finalizando em setembro de 2015 com autorização ICMBio n²6784-1, totalizando 12 coletas.

\section{Análise do conteúdo estomacal}

No laboratório de Ictiologia da Universidade do Estado de Mato Grosso, foi realizada a classificação dos exemplares através da chave de identificação de BRITSKI et al. (2007). A biometria foi realizada com o auxílio de um paquímetro para determinar o comprimento padrão (CP) (Figura 2), que tem início na ponta da mandíbula e término na base da nadadeira caudal e a altura do corpo. 


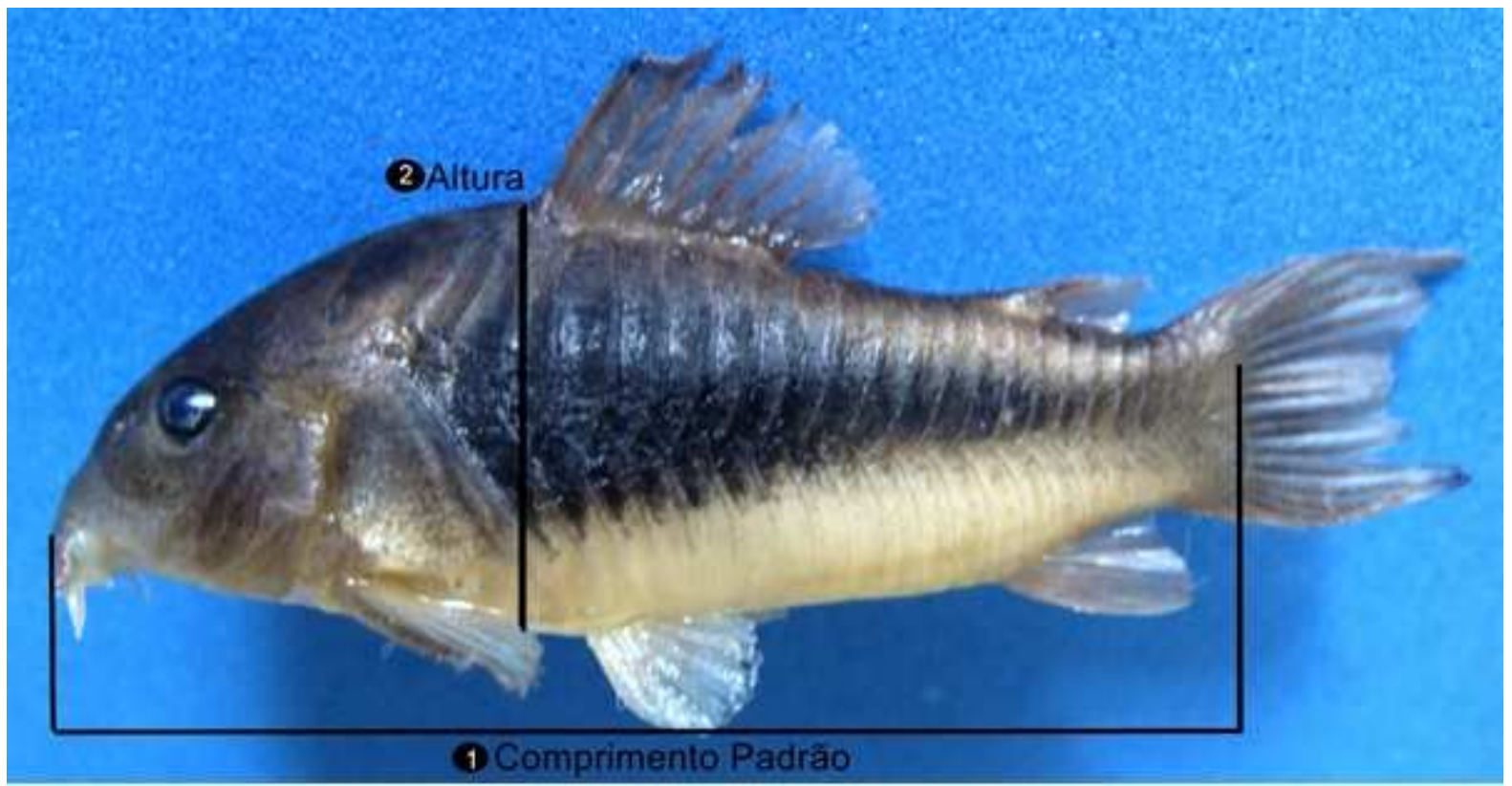

FIGURA 2. Exemplar Corydoras aeneus, representando a medida do comprimento padrão e a altura, coletado no córrego Russo, Tangará da Serra - MT. Fonte: Foto de Hevilla, 2014.

O volume total do conteúdo estomacal foi obtido pelo método de compressão do material (itens alimentares) com lâmina de vidro sobre lâmina milimétrica até uma altura conhecida $(1 \mathrm{~mm})$, para determinar o volume de cada item (HELLAWEL \& $A B E L, 1971)$. Para efeitos de classificação o GR foi representado pela proporção do volume do estômago ocupado por alimento, determinado visualmente segundo a escala: 0 vazio; $1,>0$ e $\leq 25 \%$ (quase vazio); $2,>25$ e $\leq 50 \%$ (meio cheio); $3,>50$ e $\leq 75 \%$ (quase cheio); e $4,>75 \%$ (cheio) (BRAGA, 1999).

Além do CP, a altura, a prensagem do volume total dos itens alimentares e o GR, foram analisados o tipo de sexo de cada espécime e o estádio de maturação gonadal (EMG). Para a classificação dos EMG, foi utilizada a escala descrita por VAZZOLER, (1996) que classifica os estádios da seguinte forma: Para fêmeas, foram identificados os seguintes estádios: (A) imaturo (ovários translúcidos e pequenos), (B) em maturação (ovários com oócitos opacos e pequenos ou médios), (C) maduros (ovários que ocupam completamente a cavidade celomática, apresentando oócitos com grandes dimensões e coloração amarelada), (D) esgotado (ovários com aspecto flácido e com hemorrágico). Os estádios de maturação das gônadas dos machos foram definidos como: (A) imaturo (testículos translúcidos e pequenos), (B) em maturação (testículos translúcidos, no entanto mais volumosos e com aspecto granular), (C) maduros (testículos volumosos e branqueados) e (D) esgotado.

\section{Análise de dados}

Os dados obtidos foram submetidos aos seguintes índices:

- A Frequência de Ocorrência (FO) dos itens alimentares foi determinada, através da fórmula: 


$$
F_{i}=\frac{\left(n_{i} \times 100\right)}{N}
$$

Sendo que:

$F_{i}$ : Frequência de ocorrência do item alimentar $i$ na amostra;

$n_{i}$ : números de estômagos da amostra que contém o item alimentar $i$;

$\mathrm{N}$ : número total de estômagos com conteúdo na amostra (HYSLOP, 1980).

- $\quad$ Frequência Volumétrica (FV) dos itens alimentares, foi obtida pelo método de compressão do material (itens alimentares) com lâmina de vidro sobre placa milimétrica até uma altura conhecida $(1 \mathrm{~mm})$, e o resultado convertido em milímetros $\left(1 \mathrm{~mm}^{3}=0,001 \mathrm{~mL}\right)$ (HELLAWEL e ABEL, 1971).

- Para determinação da importância dos diferentes itens alimentares foi utilizado o índice alimentar proposto por KAWAKAMI \& VAZZOLER (1980), segundo a fórmula:

$$
I A i=\left[(F i * V i) / \sum_{i=1}^{n}(F i * V i)\right] * 100
$$

Sendo que:

lai = Índice alimentar;

$\mathbf{i}=1,2, \ldots \mathrm{n}=$ determinado item alimentar;

$\mathbf{F i}=$ Frequência de ocorrência $(\%)$ do determinado item;

$\mathbf{V i}=$ Volume $(\%)$ do determinado item .

Os dados obtidos do CP e altura foram submetidos a uma análise aplicando o teste de Kolmogorov-Smirnov para determinar se a população do $C$. aeneus apresentou distribuição normal durante os dois períodos sazonais (cheia ou seca, onde $\mathrm{H} 0$ : $\mu$ seca $=\mu$ cheia; $\mathrm{H} 1: \mu$ seca $\neq \mu$ cheia) utilizando o programa BioStat (AYRES et al., 2007), e caso isto ocorra, aplicando o teste t de Student, para comparação das médias populacionais.

\section{RESULTADOS E DISCUSSÃO}

No total foram analisados 63 indivíduos da espécie C. aeneus, sendo 40 machos e 23 fêmeas, distribuídos em 35 indivíduos na seca e 28 na cheia (Figura 3), de maneira que foi possível visualizar e identificar os organismos presentes nos estômagos das espécies, (GL), o tipo do sexo e o EMG. 


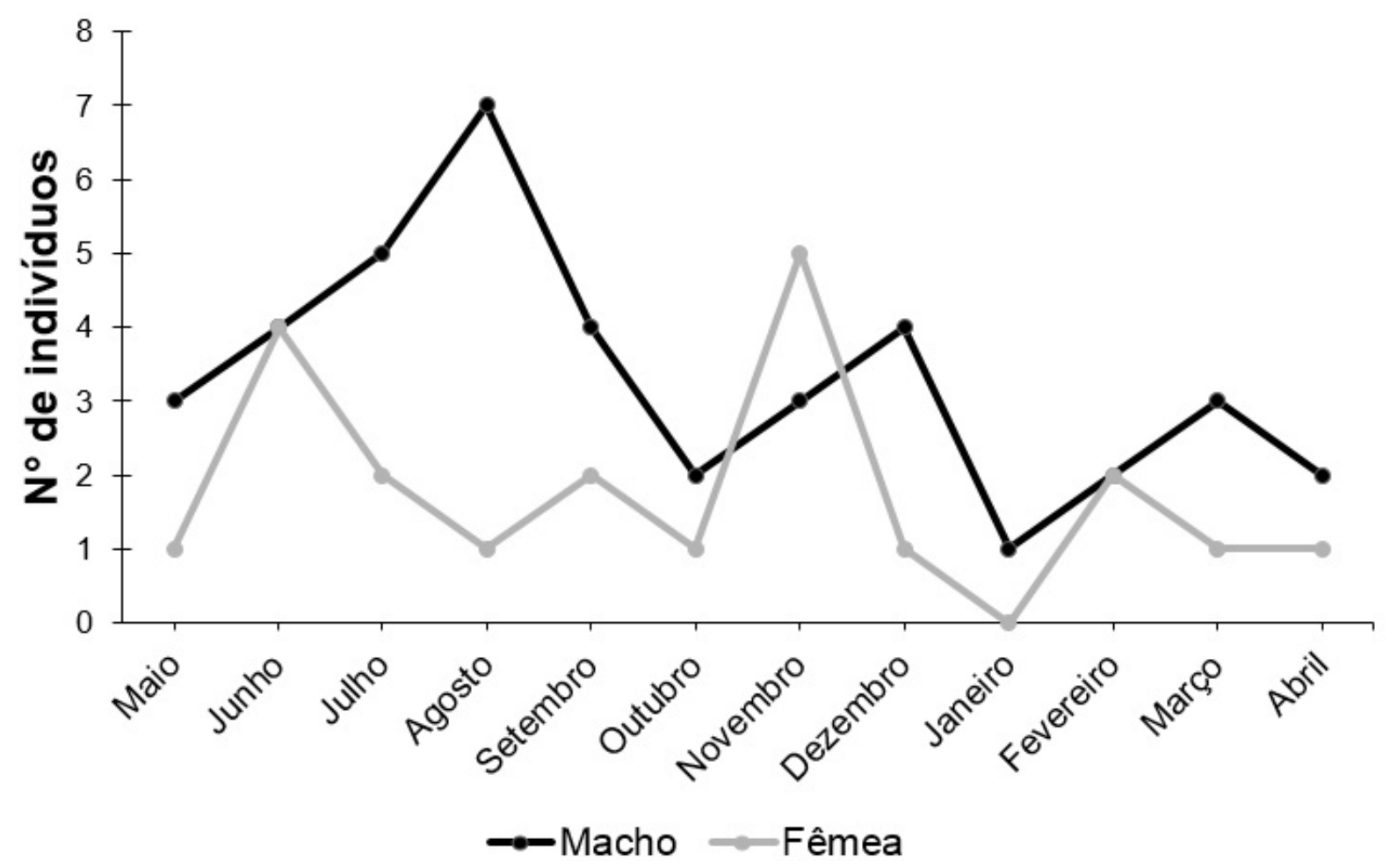

FIGURA 3. Número de indivíduos por sexo de Corydoras aeneus (Gill, 1858) analisados mensalmente, do córrego Russo, Tangará da Serra - MT

O maior $\mathrm{CP}$ atingido pelas fêmeas do $C$. aeneus no córrego durante o período de seca foi de $4,9 \mathrm{~cm}$ com média $=3,1 \mathrm{~cm}$ e os machos mediram $4,6 \mathrm{~cm}$ com média= $2,9 \mathrm{~cm}$, já para o período chuvoso o maior $\mathrm{CP}$ das fêmeas foi $4,1 \mathrm{~cm}$ com média= $3,0 \mathrm{~cm}$ e os machos mediram $3,6 \mathrm{~cm}$ com média $=2,7 \mathrm{~cm}$.

No estudo de FERREIRA \& SÚAREZ, (2015) nos riachos da bacia do rio Ivinhema, Alto rio Paraná, à mesma espécie apresentou dados semelhantes, onde o comprimento da fêmea foi maior que do macho. Constatou-se que as fêmeas do $C$. aeneus atingiram maior CP $5,1 \mathrm{~cm}$ com média $=3,8 \mathrm{~cm}$ e que os machos $4,5 \mathrm{~cm}$ e com média $=3,5 \mathrm{~cm}$.

Os testes estatísticos aplicados referentes a característica do CP da espécie C. aeneus coletada no período de seca e chuva, foram determinados após saber se a população podia ser representada por uma distribuição normal, assim, foi possível realizar o teste bilateral através da verificação de Kolmogorov-Smirnov.

O cálculo de desvio máximo (d) do $C$. aeneus coletado na estação de seca resultou em 0,1607 que é menor que o valor crítico bilateral $(0,05)$ em questão de 0,2240 confirmando que, não houve evidências suficientes para rejeitar a hipótese de que a distribuição desta população é normal. O mesmo segue para o teste desta espécie em relação a estação chuvosa, que apresentou o desvio máximo igual a 0,1144 que é menor que o valor crítico bilateral $(0,05)$ que é de 0,2500 , confirmando novamente que não houve evidências suficientes para rejeitar a hipótese de que esta outra população também é normal.

Pelo fato do CP da espécie em ambas estações serem representados por uma distribuição normal, torna-se necessário realizar um teste adicional de comparação de médias e para isto foi escolhido o teste t de Student, para determinar se existe diferença significativa no $C P$ e o resultado constatou que não houve diferença com $(p<0,05)$, apresentando $t=0,8388$ (Figura 4). Assim evidencia-se 
que o CP não está influenciando no aspecto alimentar das populações pois ambas as populações apresentaram distribuição normal sem diferença significativa em suas médias.

Em relação à altura da espécie, o teste de Kolmogorov-Smirnov realizado para os dados referente as estações de cheia e seca, ambos indicaram que a distribuição da população não é normal, para a estação chuvosa o desvio máximo resultou em 0,25 que é igual ao valor crítico bilateral $(0,05)$ que é de 0.25 , e para a seca o desvio máximo é de 0,2536 que é maior que o valor crítico bilateral que é de 0,224 .

Por este motivo não foi feito o teste de comparação de médias de Student.

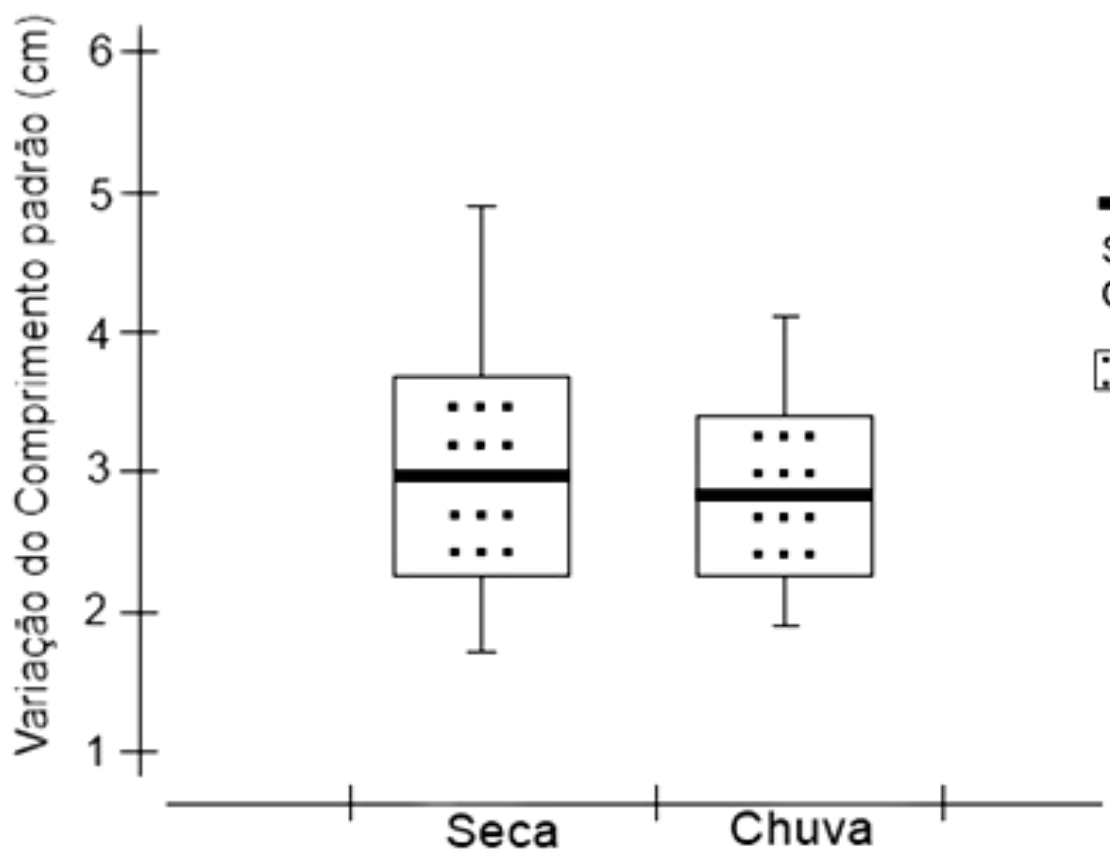

- Média

Seca $=3,0 \mathrm{~cm}$

Chuva $=2,8 \mathrm{~cm}$

:-.DDesvio Padrão

FIGURA 4. Média e o desvio padrão do comprimento da espécie $C$. aeneus durante os dois períodos sazonais.

Conforme mostra a Tabela 1, os recursos alimentares encontrados no estômago do $C$. aeneus foram classificados em quatro categorias alimentares: resto animal (larva); recursos vegetais (representados por resto de folhas, frutos e sementes); restos de insetos (de origem mista, como por exemplo himenópteros) e detritos (composto por resíduos do fundo fito e zooplâncton).

A comparação dos resultados do presente trabalho com outros estudos alimentares revelou, que existe uma plasticidade e adaptação trófica de muitas espécies de peixes de água doce, que variam conforme a disponibilidade de alimento no local (COSTA-PEREIRA et al., 2012; RESENDE et al., 2014), no corrégo Russo foi possível observar que durante a chuva aumentou o nível de insetos no local, assim aumentando também a ingestão dessa categoria pelo Corydoras aeneus, e durante a seca diminuiu o nível de insetos e aumentou o nível de folhas e outros itens alimentares no ambiente e consequentemente alterando a dieta da espécie. 
TABELA 1. Frequência de Ocorrência (FO\%), Frequência Volumétrica (FV\%) e índice de importância alimentar (IAi), do C. aeneus durante as duas estações sazonais, em Tangara da Serra.

\begin{tabular}{cccccccc}
\hline & \multicolumn{3}{c}{ Seca } & & \multicolumn{3}{c}{ Chuva } \\
\cline { 2 - 3 } \cline { 7 - 8 } Item & FO (\%) & FV (\%) & IAi (\%) & & FO (\%) & FV (\%) & IAi (\%) \\
\hline Resto Vegetal & 74,28 & 63,05 & 80 & & 42,86 & 21,53 & 24,44 \\
Resto de Insetos & 31,5 & 14,86 & 7,95 & & 46,43 & 48,91 & 60,13 \\
Detritos & 45,71 & 14,46 & 11,23 & & 10,71 & 4,01 & 0,96 \\
Resto Animal & 8,57 & 7,64 & 0,82 & & 21,43 & 25,55 & 14,47 \\
\hline
\end{tabular}

Recurso vegetal foi o item que apresentou a maior $\mathrm{FO}$ e IAi, durante o período de seca, sendo $74,28 \%$ FO e $80 \%$ IAi, porém, houve modificação no hábito alimentar durante a chuva, no qual, o item resto de insetos apresentou maior $\mathrm{FO}$ e IAi, respectivamente $46,43 \%$ e $60,13 \%$. Portanto esses itens foram considerados os principais em sua dieta.

A alimentação do $C$. aeneus está relacionada ao micro-habitat preferencial da espécie, pois é frequente coletar a mesma em locais que possui sedimentos no fundo, nas margens dos riachos com cascalhos e areia grossa. ARANHA et al., (1993) relatam que os barbilhões cefálicos têm a função sensorial para localizar a presas, no que facilita a procura de alimento, e afirma também que os itens predominantes em sua dieta são larvas aquáticas. Em RESENDE et al., (2014) a mesma espécie apresentou o hábito alimentar detritívoro, mostrando que o resultado do hábito alimentar deste trabalho é diferente dos demais estudados.

A análise do GR estomacal mostrou que houve diferença alimentar da espécie nas duas estações sazonais, sendo que no período chuvoso ocorreu maior atividade alimentar, tanto para macho como para fêmea quando comparado com período de seca. As fêmeas estavam em sua maioria no estádio $2(50 \%)$, e os machos no estádio 3, respectivamente $75 \%$ para GR. No período de seca a maioria dos indivíduos machos analisados estavam no estádio 1 (25\%), enquanto que a maioria das fêmeas no mesmo período estavam no estádio 3 , ou seja, $75 \%$ do volume do estômago estava cheio de alimento (Figura 5).

O GR estomacal mostrou que durante o periodo chuvoso os indivíduos de $C$. aeneus coletados no corrégo Russo apresentaram maior consumo de alimentos, principalmente restos de insetos. Observa-se que no período da chuva houve uma grande disponibilidade de inseto no local, no qual acabam caindo no rio e aumentam a disponibilidade de alimento.

$O$ fato das fêmeas terem se alimentado menos que os machos podem estar relacionados com o fator reprodutivo, pois para CAMARA et al., (2011) durante o período reprodutivo, ocorre uma diminuição na atividade alimentar em muitas espécies de peixes. Os machos têm o hábito de se alimentarem mais durante a época de reprodução do que as fêmeas, por isso apresentam o grau de repleção superior. Isso pode ser explicado, pelo maior gasto de energia das fêmeas durante $o$ processo reprodutivo, enquanto que os machos investem a energia em crescimento (HUNTINGFORD et al., 2001). 
A

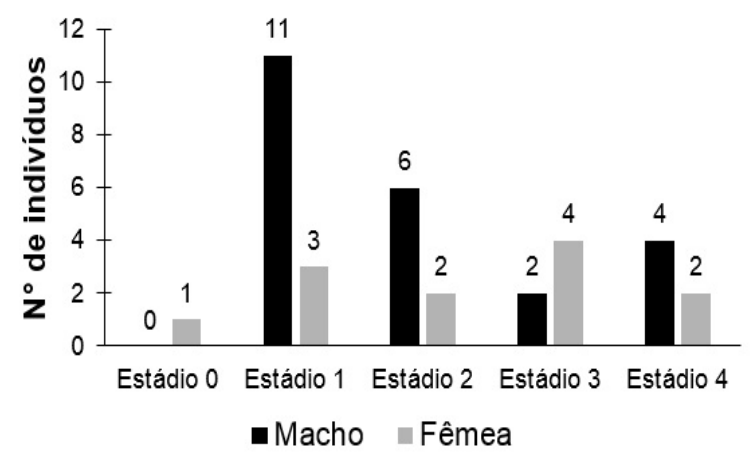

B

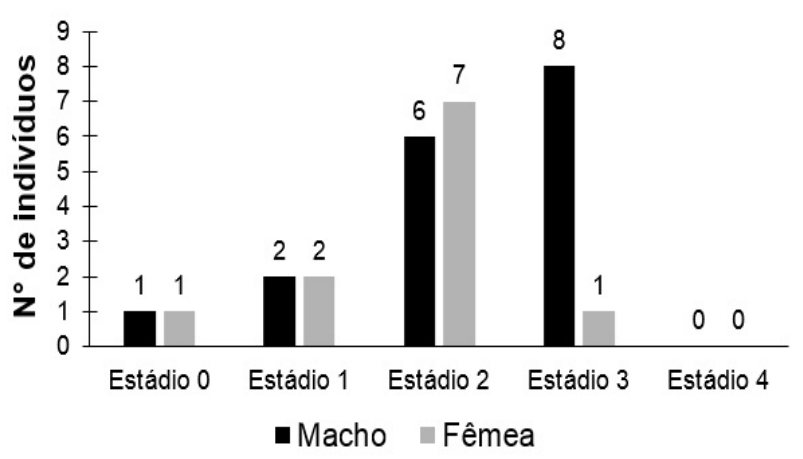

FIGURA 5. Grau de repleção estomacal do $C$. aeneus em duas estações sazonais, (A) seca e (B) chuva, no córrego Russo, Tangará da Serra - MT.

Para EMG de $C$. aeneus, foi possível notar que tanto no período de seca como de chuva, os indivíduos machos apresentaram maior maturação gonadal do que as fêmeas. Conforme a figura 6 , no período de seca $48 \%$ dos machos encontravam-se no estádio C, (Maduro), enquanto $42 \%$ das fêmeas estavam no estádio D (Esgotado). Diferentemente do período chuvoso, onde a 59\% dos machos estavam com suas gônadas esgotadas e as fêmeas $45 \%$ encontravam-se tanto no EMG como esgotado.

Essa frequência relativa dos EMG indica que a desova é do tipo parcelada. Nos estudos de RONDINELLI \& BRAGA (2009), eles constataram desova parcelada em $C$. aeneus, $A$. fuscogutattus e $C$. flaveolus, respectivamente. $O$ tipo de desova pode ter inúmeras táticas que integram as estratégias reprodutivas (VAZZOLER, 1996).

A

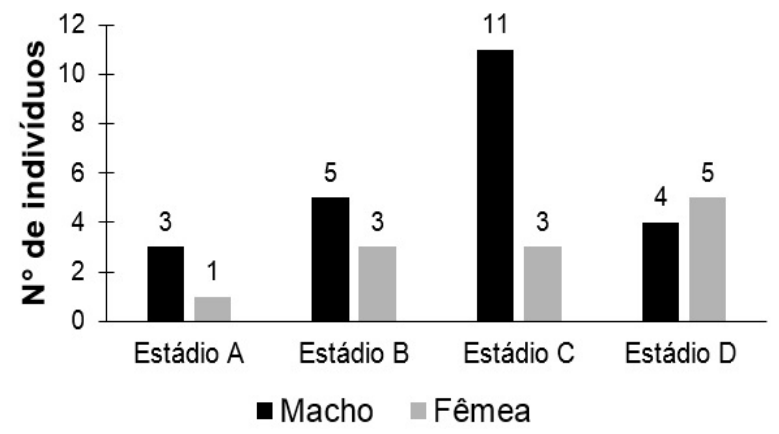

B

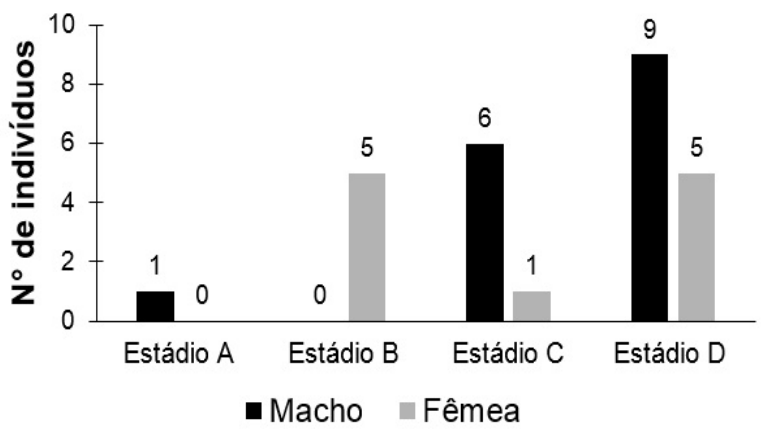

FIGURA 6. Estádio de maturação gonadal (EMG) do $C$. aeneus nas duas estações sazonais, $(A)$ seca e $(B)$ chuva, no córrego Russo, Tangará da Serra MT.

Os dados mostram que a partir de estudos como este, é possível saber o que uma determinada espécie utiliza como alimento principal em seu ecossistema. Compreendendo que isso depende totalmente do local, pois se o mesmo estiver sofrendo com poluições a diversidade de espécies nesse ambiente vai ser baixa. Por isso se tornam importantes estudos voltados nessa área. CARMO et al., (2016) dizem que há pouco conhecimento disponível sobre a ictiofauna em estudos, há necessidade de estudos futuros que permitam verificar se os padrões da dieta alimentar neste estudo se repetem futuramente e em outros locais. 


\section{CONCLUSÃO}

Foram identificadas quatro categorias alimentares para a espécie Corydoras aeneus coletadas no córrego Russo, no município de Tangará da Serra - MT, sendo elas, resto animal, recursos vegetais, restos de insetos e detritos. Através desse estudo nota-se que a espécie apresentou uma grande flexibilidade alimentar.

O hábito alimentar constituiu predominante de recurso vegetal durante a seca por ser o item que apresentou a maior FO e IAi, já para o período chuvoso o item resto de inseto foi o que apresentou a maior $\mathrm{FO}$ e IAi, o que mostrou que houve diferença em sua alimentação durante os dois períodos sazonais. Portanto esses itens foram considerados principais em sua dieta.

Após o período da chuva houve uma grande diversidade de itens alimentares, isso ocorre por que através da chuva os restos de folhas, frutos, insetos acabam caindo no rio e aumentam a disponibilidade de alimento.

O estudo da dieta é de grande importância determinando que a alimentação neste sistema de vegetação em abundância ocasiona essa mudança, em decorrência da queda nos índices alimentares de insetos e aumento nos índices dos restos vegetais.

O período reprodutivo é do tipo parcelado, o que é uma vantagem para a espécie pois esta estará em atividade reprodutiva o ano inteiro, aumentando a chance de sobrevivência da espécie no local.

\section{AGRADECIMENTOS}

Agradecimentos ao professor Dr. Waldo Pinheiro Troy por ceder o espaço do laboratório para o andamento da pesquisa. A $\operatorname{Dr}^{\mathrm{a}}$ Divina Sueide e Dr. Luiz Antônio pela orientação do trabalho.

A toda a equipe do laboratório LIP - Laboratório de Ictiologia e Piscicultura, da Universidade do Estado de Mato Grosso, campus de Tangará da Serra, pelo apoio nas coletas dos peixes e ensinamentos adquiridos na prática.

\section{REFERÊNCIAS}

ARANHA, J. M. R.; CARAMASCHI, E. P.; CARAMASCHI, U. Ocupação espacial, alimentação e época reprodutiva de duas espécies de Corydoras Lacépède (Siluroidei, Callichthyidae) coexistentes no rio Alambari (Botucatu, São Paulo). Revista Brasileira de Zoologia, v. 10, n. 3, p. 453-466, 1993. Disponível em: <http://dx.doi.org/10.1590/S0101-81751993000300013>.

AYRES, M.; AYRES, M. J.; AYRES, D. L.; SANTOS, A. de A. dos. BioEstat 5.0: Aplicações estatísticas nas áreas das ciências biológicas e medicas. Belém: Sociedade Civil Mamiraua / CNPq. 2007.

BARROS, N. H. C.; LIMA, L. T. B. ARAÚJO, A. S.; GURGEL, L. L.; CHELLAPPA, N. T.; CHELLAPPA, S. Estudos sobre as táticas e as estratégias reprodutivas de sete espécies de peixes de água doce do Rio Grande de Norte, Brasil. Holos, v. 3, p. 84103, 2016. DOI: $10.15628 /$ holos.2016.3648.

BEVERTON, R. H. J.; HOLT, S. J. A review of the life spans and natural mortality rates of fish in nature and their relation to growth and other physiological characteristics. WOLSTENHOLME, G. E. W.; CONNOR, M. O. eds. CIBA Colloquium on Ageing. London, Churchill. v. 5, p.142-180, 1959. DOI: 10.1002/9780470715253.ch10. 
BRAGA, F. M. S. Idade, crescimento e taxas de mortalidade de Astyanax bimaculatus (Characidae, Tetragonopterinae) na represa de Barra Bonita, rio Piracicaba (SP). Naturalia, v. 24, p. 239-250, 1999.

BRITSKI, H. A.; SILIMON, K. Z. S.; LOPES, B. S. Peixes do Pantanal: manual de identificação. 2. ed. Brasília, DF: Embrapa Informação Tecnológica, 2007.

CAMARA, E. M.; CARAMASCHI, E. P.; PETRY, A. C. 2011. Fator de condição: bases conceituais, aplicações e perspectivas de uso em pesquisas ecológicas com peixes. Oecologia Australis, v.15, p. 249-274. DOI: 10.4257/oeco.2011.1502.05.

CANAN, B.; PESSOA, E. K. R.; VOLPATO, G. L.; ARAUJO, A.; CHELLAPPA, S. Feeding and reproductive dynamics of the damselfish, Stegastes fuscus in the coastal reefs of northeastern Brazil. Animal Biology Journal, v. 2, p. 113-126, 2011. Disponível

em: $<$ https://www.researchgate.net/publication/221931538_Feeding_and_reproductive_d ynamics_of_the_damselfish_Stegastes_fuscus_in_the_coastal_reefs_of_northeaster n_Brazil>.

CANAN, B.; NASCIMENTO, W. S.; SILVA, N. B.; CHELLAPPA, S. Morphohistology of the digestive tract of the damsel fish, Stegastes fuscus (Osteichthyes: Pomacentridae). The Scientific World Journal, v. 2012, p. 1-9, 2012. DOI: $10.1100 / 2012 / 787316$.

CARMO, M. A. F.; BARRELLA, W.; RAMIRES, M.; CLAUZET, M.; SOUZA, U. P. Ictiofauna de riachos da Reserva de Desenvolvimento Sustentável da Barra do UnaPeruíbe-SP. Unisanta BioScience, v. 5, n. 1, p. 56-65, 2016.

CHELLAPPA, S.; NASCIMENTO, W. S.; BARROS, N. H. C.; ARAÚJO; A. S., CHELLAPPA, N.T. Reproductive characteristics and strategies of freshwater fish species from the semiarid region of Brazil. Animal Biology Journal, v. 4, p. 85-114, 2013.

COSTA-PEREIRA, R.; ROSA, F. R.; RESENDE, E. K. Estrutura Trófica da comunidade de peixes de riachos da porção Oeste da Bacia do Alto Paraná. Dados eletrônicos. Corumbá: EMBRAPA Pantanal, 2012.

DALLACORT, R.; MARTINS, J. A.; INOUE, M. H.; FREITAS, P. S. L.; COLETTI, A. J. Distribuição das chuvas no município de Tangará da Serra, médio norte do Estado de Mato Grosso, Brasil. Acta Scientiarum. Agronomy, v. 33, n. 2, p. 193-200, 2011. Disponível em: < http://dx.doi.org/10.4025/actasciagron.v33i2.5838>. Doi: 10.4025/actasciagron.v33i2.5838

FERREIRA, F. S.; SÚAREZ, Y. R. Estrutura populacional e aspectos reprodutivos de Corydoras aeneus em riachos da bacia do Rio Ivinhema, Alto Rio Paraná. Iheringia Série Zoologia, v. 105, n. 4, 2015. Doi: 10.1590/1678-476620151054474483

FROESE, R.; PAULY, D. Fish Base, 2013. Disponível em: http://www.fishbase.org. Acesso em junho de 2016. 
GANDINI, C. V.; BORATTO, I. A.; FAGUNDES, D. C.; POMPEU, P. S. Estudo da alimentação dos peixes no rio Grande à jusante da usina hidrelétrica de Itutinga, Minas Gerais, Brasil. Iheringia, Série Zoologia, v. 102, n. 1, p. 56-61, 2012. Disponível em: <http://dx.doi.org/10.1590/S0073-47212012000100008>.

HELLAWELL, J.; ABEL, R. A rapid volumetric method for the analysisof the food of fishes. Journal of Fish Biology, v. 3, p. 29-37, 1971. DOI: 10.1111/j.10958649.1971.tb05903.x.

HUNTINGFORD, F. A.; CHELLAPPA, S.; TAYLOR, A. C.; STRANG, R. H. C. Energy reserves and reproductive investment in male three spined sticklebacks, Gasterosteus aculeatus. Ecology of Freshwater Fish. v. 10, n. 2, p. 111-117, 2001. DOI: 10.1034/j.1600-0633.2001.100206.x.

HYSLOP, E.J. Stomach contents analysis - a review of methods and their applications. Journal of Fish Biology, v. 17, p. 411-429, 1980. DOI: 10.1111/j.10958649.1980.tb02775.x.

KAWAKAMI, E.; VAZZOLER, G. Método gráfico e estimativa de índice alimentar aplicado no estudo de alimentação de peixes. Boletim do Instituto Oceanográfico, São Paulo, v. 29, n. 2, p. 205-207. 1980. Disponível em: < http://dx.doi.org/10.1590/S0373-55241980000200043>.

LIRA, G. Conhecendo Mato Grosso - O Estado e a Capital Cuiabá. 2011. Disponívelem:<http://www.gilsonlirapoesias.com.br/site/pdf/conhecendomatogrossovol1.pdf>.

NASCIMENTO, W. S.; YAMAMOTO, M. E.; CHELLAPPA, S. Proporção sexual e relação peso-comprimento do peixe anual Hypsolebias antenori (Cyprinodontiformes: Rivulidae) de poças temporárias da região semiárida do Brasil. Biota Amazônia, v. 2, n. 1, p. 37-44, 2012. Disponível em: <http://dx.doi.org/10.18561/2179-5746/biotaamazonia.v2n1p37-44>. Doi: $10.18561 / 2179-5746$.

PESSOA, E. K. R.; SILVA, N. B., CHELlAPPA, N. T., SOUZA, A. A. Morfologia comparativa do trato digestório dos peixes Hoplias malabaricus e Hypostomus pusarum do açude Marechal Dutra, Rio Grande do Norte, Brasil. Biota Amazônia, v. 3, n. 1, p. 48-57, 2013. Disponível em: < http://dx.doi.org/10.18561/21795746/biotaamazonia.v3n1p48-57>.

RESENDE, J. C.; SANTANA, J. S; ESPÍNDOLA, E. L. G. Qualidade da água e ictiofauna do córrego São José, São Carlos (SP): ênfase nos impactos gerados por lixão desativado. Ciência e Natura, v. 36, n. 3, p. 387-300, 2014. DOI:10.5902/2179460X13170.

RONDINELI, G. R.; BRAGA, F. M. S. Biologia populacional de Corydoras flaveolus (Siluriformes, Callichthyidae) no Rio Passa Cinco, sub-bacia do Rio Corumbataí, São Paulo, Brasil. Biota Neotropica, p. 45-53, 2009. Disponível em: < http://dx.doi.org/10.1590/S1676-06032009000400004>. 
SERRA, J. P; FARIA, F.; CAMPOS, S.; SILVA, A. L. C. Composição e estrutura da comunidade de peixes de um afluente do rio Tietê, bacia do Alto rio Paraná. Revista Agrogeoambiental, v. 7, n. 1, 2014. Disponível em: < http://dx.doi.org/10.18406/2316-1817v7n12015678>.

SOUZA, F. D.; SANTOS, C. J. D.; MATEUSSI, N. T. B.; ZUANON, L. A.; OTA, R. R. Variação espacial na estrutura da ictiofauna em Dois Riachos na Bacia do Rio Pirapó/Spatial variation in the structure of ichthyofauna on Two Streams in Pirapó River Basin. Revista Meio Ambiente e Sustentabilidade, v. 7, n. 3, p. 366-382, 2014. em:

http://www.grupouninter.com.br/web/revistameioambiente/index.php/meioAmbiente/a rticle/view/237/162>.

SOUZA, W. D.; SILVA, S. A. A. S; BILCE, J. M. Dieta natural de Serrapinnus kriegi (Schindler, 1937), (Characidae: Cheirodontinae) no córrego Ribeirão, Altos Tapajós, Brasil. Revista de Ciência Agro-Ambientais, v.9, n. 1, p.97-108,2011. Disponível em: <http://portal.unemat.br/media/oldfiles/prppg/docs/484.pdf>.

VASCONCELOS, L.; DUARTE, L.; VEIGA, B.; VALARIÉ, P.; CASIMIRO, I.; CUAMBA, B.; OLÍMPIO, M. Ecossistemas, Água e Participação-estratégias nas políticas de recursos hídricos do Portugal, Brasil e Moçambique. Revista Online Da Sociedade Portuguesa de Ecologia. Disponível em: http://speco. fc. ul. pt/revistaecologia_2_art_3_3. html, 2011.

VAZZOLER, A. E. A. M. Biologia da reprodução de peixes teleósteos: teoria e prática. Maringá: EDUEM; São Paulo: SBI, 1996. 169p. 